\title{
LA NOCIÓN DE IMPERIO DE LA LEY EN FRANCISCO LAPORTA Y LIBORIO HIERRO
}

\author{
Gema Marcilla Córdoba \\ Universidad de Castilla-La Mancha
}

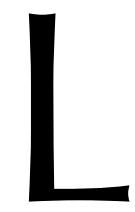

APORTA y HIERRO han realizado valiosísimas contribuciones a una noción tan central para la comprensión del Derecho como es la de imperio de la ley. Ello incluye el tratamiento sistemático de las manifestaciones de la crisis del Derecho legal y de las posibilidades y límites de una ciencia de la legislación. Coinciden ambos en una idea ilustrada, democrático-legalista y positivista del imperio de la ley, en confrontación con una visión constitucional-principialista y antipositivista del concepto. Concisamente, a juicio de los autores, el Derecho autoriza al legislador a crear normas generales destinadas a ser lealmente aplicadas por los jueces, a fin de que el Derecho pueda garantizar principios y valores consensuados democráticamente; cuando menos, la igualdad formal y la certeza ${ }^{1}$.

«Imperio de la ley» alude a un «deber ser», a un ideal regulativo sobre el ejercicio del poder. Contiene «un conjunto de exigencias éticas para el poder y para el Derecho» ${ }^{2}$. Es, pues, un concepto normativo que permite evaluar el orden jurídico vigente o una propuesta de organización jurídica ${ }^{3}$. Hay consenso, además, en que la legitimidad del poder político depende en primera instancia en su sumisión a una normatividad preconstituida, es decir, en «un gobierno de las leyes» por encima del «gobierno de los hombres».

Además de normativo, el concepto de imperio de la ley es de carácter histórico: la teoría del contrato social de los siglos XVII y XVIII introduce el aspecto definitorio de la noción moderna de imperio de la ley, la secularización del Derecho. Con ella, la legitimidad del Estado y del Derecho se desvincula de toda fuente sobrenatural, y se dota de un fundamento netamente humano: el consentimiento de los individuos. Sin embargo, son compatibles con el contractualismo moderno cuando menos tres versiones: HOBBES (1651) la identifica con el aseguramiento de la convivencia pacífica por el Leviathan a cambio de la renuncia incondicionada de los individuos a su libertad; LOCKE (1690), con un compromiso entre las instituciones y los individuos, que ceden solo limitadamente su libertad; y Rousseau (1762), con la voluntad ge-

\footnotetext{
${ }^{1}$ La certeza es condición de la autonomía personal, LAPORTA, 2007: 17 y ss.

2 Ibid., 12.

3 Para FerRajoli y Prieto el «imperio de la ley» en el Estado constitucional posibilita reflexionar sobre las normas válidas, vigentes y justas. Es un enfoque no «legalista» pero «positivista» porque distingue entre los modelos político-jurídicos pre constituidos (validez) y las críticas y alternativas a dichos modelos (justicia). Vid. FERRAJOLI, 2011; PRIETO, 2013.
} 
neral del pueblo. Bajo el imperio de la ley no hay enfrentamiento entre el poder del soberano y la libertad de los individuos. En la ley el pueblo entero expresa su consentimiento, de modo que, en esta noción democrática de imperio de la ley, la libertad individual se realiza a través de la libertad política. De las tres concepciones mencionadas, HIERRO y LAPORTA suscriben la rousseaniana, cuya racionalidad queda reforzada por las cualidades formales de la legislación: unicidad, claridad, sencillez, publicidad, y muy particularmente, generalidad y abstracción ${ }^{4}$. LAPORTA resalta que tras la noción de ley como norma general y abstracta se halla la exigencia kantiana de universalidad de la pauta moral: «La razón solo puede hablar con leyes generales en el sentido de que lo que se predica de algo tiene necesariamente que ser predicado de todo aquello que tenga las mismas propiedades que ese algo». Así, la generalidad sirve a la igualdad formal; es decir, a la imparcialidad y al fin de las diferencias. La abstracción, por su parte, es la generalidad en el tiempo; es decir, consiste en la «determinación, de una vez para siempre, de los efectos que el ordenamiento atribuye a un cierto tipo de acto o hecho», generando previsibilidad. La abstracción es contraria a las leyes poco estables y por supuesto a las retroactivas ${ }^{5}$. Por lo demás, la noción democrático-legalista de imperio de la ley no solo opera como ideal regulativo de la legislación, sino también como ideal regulativo de la jurisdicción, y condición de su legitimidad, fundamentada en su vinculación exclusiva a la ley. MONTESQUIEU (1748) o BECCARIA (1764) enfatizan la estrecha relación entre ambos polos del imperio de la ley.

La noción ilustrada del imperio de la ley tuvo una extraordinaria proyección práctica en el siglo XIX, con la diferencia de que en Norteamérica se prefirió la versión «lockeana», instaurándose el judicial review, mientras que en Europa prevaleció la «rousseaniana», con una jurisdicción encadenada a los preceptos de la ley para no incurrir en la restitución de antiguos privilegios. El primer positivismo jurídico refuerza el concepto democrático-legalista de imperio de la ley: el estatuto científico de la reflexión jurídica depende de poder delimitar netamente el Derecho que es (la ley, producto de la asamblea) y el Derecho que debe ser (principios constitucionales meramente programáticos).

La confianza ilustrada en la legislación da paso a su veneración decimonónica, y el mito se mantiene casi incólume pese a los constantes desmentidos de la realidad: la motorización legislativa característica de funciones estatales más complejas se traduce, de un lado, en el empeoramiento de la calidad formal de la legislación y, de otro lado, en el protagonismo del ejecutivo. La ley, destaca LAPORTA, se pierde «en una selva de normas jurídicas de una fuerza y un ámbito de validez equivalentes al de ella y que, sin embargo, no son producidas por ese órgano legislativo» ${ }^{6}$. Asimismo, el retroceso del Estado-nación «implica — afirma HIERRO — una nueva y distinta quiebra del imperio de la ley como expresión de la voluntad general porque las normas comunitarias (Reglamentos y Directivas) cuya vigencia se impone desplazando, en su ámbito de competencia, las leyes internas de cada Estado no son leyes que emanen de ningún poder soberano o representativo de un soberano, no son expresión de ninguna voluntad

\footnotetext{
4 J. J. RousSEAu, 1762: 431-432.

LAPORTA, 1999: 324.

${ }^{6}$ Ibid.
} 
general» $\gg^{7}$. Y tan pernicioso como el deterioro de la calidad formal y el déficit democrático de las leyes lo es la ausencia de mecanismos institucionales que permitan —como resalta HIERRO- realizar análisis prospectivos y evaluativos de la eficacia, efectividad y eficiencia de las leyes ${ }^{8}$.

La crisis de la ley desde el siglo XIX hasta nuestros días nada tiene que ver con el cáncer del imperio de la ley durante los totalitarismos del periodo de entreguerras: concentración de todos los poderes en el ejecutivo, desprecio al parlamento, judicialismo, habitualidad de los crímenes de estado y guerra con pretensiones imperialistas. El hecho es, sin embargo, que tras la Segunda Guerra Mundial se produce un giro a favor de una concepción constitucionalista del imperio de la ley. La concepción democrático-legalista fue culpabilizada — con escaso fundamento a juicio de HIERRO y LAPORTA 9 - de mixtificar la realidad; la ley se había presumido tan perfecta que ni se sospechaba que el poder pudiera usarla para cometer atrocidades ${ }^{10}$. Esta severa crítica al legalismo conduce al constitucionalismo, como cultura jurídica contemporánea preeminente: la garantía de los derechos de los individuos se realiza mejor a través de instituciones fundamentadas en la noción lockeana de imperio de la ley, con un sistema de judicial review ${ }^{11}$.

HIERRO y LAPORTA coinciden en que el constitucionalismo degrada a la ley ${ }^{12} \mathrm{y}$, en consecuencia, al reverso de la racionalidad legislativa, la racionalidad de la jurisdicción: «Si asumimos la indiscutible fuerza normativa de las constituciones; y si añadimos a ello la expansiva fuerza normativa de los principios, será obligado concluir que las leyes corren el riesgo de perder toda perentoriedad normativa, esto es, todo su imperio, para ceder paso al imperio del intérprete» ${ }^{13}$. Aunque el mayor problema, para LAPORTA, no es la discrecionalidad sino las contradicciones con la democracia de la propia filosofía del constitucionalismo; el plus de legitimidad democrática de la Constitución frente a la ley se argumenta con la teoría de los dos momentos: el constituyente, emparentado con la original position, y el legislativo, en el que los actores «se encenagan en sus estrechos intereses partidistas». Sin embargo, los padres constituyentes suelen ser los mismos representantes que legislan, sin velo de ignorancia, ni debate en situación ideal de diálogo. Desmitificado el momento constituyente — sostiene LAPORTA - cabría justificar la supremacía constitucional, bien afirmando que la Constitución es la norma democrática positiva superior del ordenamiento por-

7 HIERRO, 1996: 34.

8 HiERro, 2001: 2003.

9 «Hay partes enteras del Derecho nacionalsocialista que nunca llegaron a tener la categoría de Derecho válido [...] todas esas leyes que aplicaban un trato infrahumano o les negaban los derechos humanos a ciertos hombres», HIERRO, 2002: 283 y 288.

10 La idea democrática de imperio de la ley sirve a KANT para justificar cualquier Derecho positivo, porque el contrato social no enuncia un fundamento bistórico de la constitución civil, sino una idea de razón práctica: el deber de obedecer al poder legislativo existente, sea cual fuera en origen, KANT, 1797: 143 y 150.

11 HIERRO, 2002: 283.

12 LAPORTA, 2007: 219.

13 Hierro, 1996: 40. En todo caso, el autor coincide en la necesidad de aceptar cambios en el modo de identificación del Derecho en el Estado constitucional: «Nuestros sistemas jurídicos [...] han positivizado principios morales racionalmente fundados y de pretensión universal; [no] tengo ninguna duda de que ello tiene trascendencia en la identificación de lo que es Derecho válido y de que añade dimensiones éticas nuevas y más complejas en los procesos jurídicos de toma de decisiones», HIERRO, 2002: 298. 
que ella misma así lo establece; bien diciendo que la Constitución es la norma suprema porque contiene valores y principios de justicia, de modo que los principios constitucionales «valen» no por ser jurídicos, sino por ser morales. Las derivadas son difíciles de asumir desde una perspectiva ilustrada: la primera afirmación supone sostener acríticamente la mayor legitimidad de la Constitución. La segunda, tendría dos consecuencias: «En primer lugar, que el origen democrático de la norma nos trae, en realidad, sin cuidado, y, en segundo lugar, que hemos abandonado la Constitución y navegamos ya en el mar abierto de la argumentación moral» ${ }^{14}$, produciéndose una «sobreconstitucionalización»: «Una enorme cantidad de problemas que hasta ahora se planteaban y resolvían en el nivel de la legalidad, se proyectan ahora hacia la Constitución y apelan a ella [...] la ley está en permanente interinidad y en una posición subalterna, porque es interpretada y contemplada no por sí misma sino como una suerte de sospechosa permanente que hay que vigilar a la luz de la Constitución» ${ }^{15}$. En este sentido, es interesante reflexionar sobre el alcance y límites de las técnicas legislativas: la recuperación de una idea democrático-legalista del imperio de la ley requiere técnicas que reporten tanta claridad como sea posible para dificultar la elusión de la ley por los jueces en nombre de principios constitucionales. En otros términos, a mayor racionalidad de la ley en todas las fases (prelegislativa, legislativa y poslegislativa) más evidentes serán los supuestos de activismo judicial parapetados en una retórica tan grandilocuente como falaz.

Sin embargo, la calidad de las leyes no es la solución al problema de la discrecionalidad judicial, porque el paradigma de Estado Constitucional ha modificado el significado del imperio de la ley ${ }^{16}$. El concepto de imperio de la ley del constitucionalismo, pese al criterio general de LAPORTA y HIERRO, no es contradictorio con el ideal democrático-legalista de imperio de la ley. El legislador impone su visión política dentro de unos límites y el juez, una vez comprobado el respeto de la Constitución, se rige por la ley. El constitucionalismo no es incompatible con la regla de las mayorías; solo introduce el sistema de checks and balances entre los responsables de legislar y aplicar el Derecho. El propio LAPORTA no aboga por «prescindir pura y simplemente de la idea de Constitución». De lo que se trata tal vez es de reformular el ámbito propio (de ley y constitución) postulando una nueva «pleamar» de la ley, así como la correspondiente «bajamar» de la Constitución ${ }^{17}$. El constitucionalismo no postula que la jurisdicción degrade arbitrariamente a la ley, haciendo de la necesidad (ponderar en los casos difíciles) virtud (prescindir de las razones legales). Por lo demás, la tensión entre una noción democrático-legalista y una constitucionalista-principialista del imperio de la ley no es quizás tanto una cuestión relativa a la vigencia del Estado constitucional (aunque sí propiciada por este), sino relativa a la concepción del Derecho. Desde posiciones legalistas lo crucial para mantener los valores asociados al imperio de la ley (igualdad formal, seguridad jurídica, autonomía) es disponer de criterios para discriminar entre razones jurídicas y razones extrajurídicas ${ }^{18}$. Desde posiciones principialistas, los

\footnotetext{
14 LAPORTA, 1999: 328-329.

15 Ibid., 322.

16 PRIETO, 1998: 44.

17 LAPORTA, 2001: 460 y 478 y ss.; LAPORTA, 2007.

18 La importancia de mantenerse en el positivismo metodológico «reside, parafraseando a Kant, en limitar la Ciencia del Derecho, para reservar un sitio a la moral», HiERRO, 2002: 298.
} 
mismos ideales asociados al imperio de la ley descansan en la prioridad, que no en la exclusividad, de las razones jurídicas, en una argumentación que respete una serie de requisitos de racionalidad.

En conclusión, en muchos de sus trabajos LAPORTA y HIERRO han resaltado el modelo ilustrado-rousseaniano de ley como un invento formidable con capacidad para realizar el postulado principal de la cultura jurídica moderna; es decir, la idea de imperio de la ley o de Estado de Derecho en sentido estricto a la que se refería Elías DíAz: democracia, separación de poderes y derechos individuales. En efecto, el imperio de la ley significa que el poder político carece de otro fundamento que el consentimiento de individuos libres e iguales, que estiman que merece la pena consensuar por mayoría algunos límites a la libertad en aras de una convivencia pacífica. En un escenario de separación de poderes, la ley, expresión de la voluntad del pueblo y dotada de una serie de características racionales como la generalidad y abstracción, es idónea para desempeñar ese significativo papel. De un lado, embrida a la maquinaria del poder ejecutivo, que debe poner en marcha el contenido legal y en ningún caso contravenirlo; asimismo, somete al poder judicial restringiendo su función a la solución de los casos particulares tomando a la ley general como única premisa mayor del razonamiento aplicativo. Reforzar la calidad de los procedimientos democráticos y la calidad formal e instrumental de las leyes es sin duda un reto para lograr una sociedad donde se cumplan efectivamente los valores anexos al imperio de la ley. Sin embargo, en sus últimos ensayos, los autores encuentran poco realista seguir confiando en la ley en sociedades globalizadas ${ }^{19}$. Más aún, ¿่sugieren sus palabras que el propio ideal de imperio de la ley, ya sea en su versión legalista o constitucionalista, estando tan vinculado a concepto de Estado-nación, está próximo a caducar? ${ }^{20}$.

\section{BIBLIOGRAFÍA CITADA}

FerRajoli, L., 2011: «Principia Iuris», Teoría del Derecho y de la Democracia, 3 vols., Madrid: Trotta.

Hierro, L., 1996: «El imperio de la ley y la crisis de la ley», en Estado de Derecho. Problemas actuales (1998), 2. ${ }^{a}$ ed., 2001, México: Fontamara.

- 2001: Justicia, igualdad y eficiencia, Madrid: Centro de Estudios Políticos y Constitucionales.

- 2002: «¿Por qué ser positivista?», Doxa. Cuadernos de Filosofía del Derecho, núm. 25, 263 300.

- 2003: La eficacia de las normas jurídicas, Barcelona: Ariel.

— 2014: «Justicia global y justicia legal: ¿tenemos derecho a un mundo justo», en A. RuIZ Miguel (ed.), Entre Estado y Cosmópolis. Derecho y justicia en un mundo global, Madrid: Trotta.

KANT, I., 1797: La metafísica de las costumbres, A. CoRTinA y J. CONILl (eds.), 1989, Madrid: Tecnos.

19 LAPORTA, 2014: 41-79; HIERRO, 2014: 83-120.

20 «Suavizar los conceptos, disminuir su fuerza, atemperar sus aristas, no evita, sino que por el contrario exacerba los grandes problemas que anidan en el Derecho, que son, aunque se sea tan poco consciente de ello, problemas filosóficos», LAPORTA, 2014: 79. 
LAPORTA, F., 1999: «Materiales para una reflexión sobre la racionalidad y crisis de la ley», Doxa. Cuadernos de Filosofía del Derecho, núm. 22, 321-330.

- 2001: «El ámbito de la Constitución», Doxa. Cuadernos de Filosofía del Derecho, núm. 24, 459-484.

- 2007: El imperio de la ley. Una visión actual, Madrid: Trotta.

- 2014: «Gobernanza y soft law: nuevos perfiles jurídicos de la sociedad internacional», en A. Ruiz Miguel (ed.), Entre Estado y Cosmópolis. Derecho y justicia en un mundo global, Madrid: Trotta.

PRIETO, L., 1998: «Del mito a la decadencia de la ley. La ley en el Estado constitucional», en Ley, principios, derechos, Madrid: Dykinson.

- 2013: El constitucionalismo de los derechos, Madrid: Trotta.

Rousseau, J. J., 1762: «El contrato social», Libro II, Cap. IV, en Escritos de combate, trad. y notas de S. MASÓ, Introducción de G. BEnREKASSA, Madrid: Alfaguara. 